KAROLINA RAK ${ }^{1}$

\title{
O DE-ORIENTALIZACJI „SPOJRZENIA” SZTUKA WIZUALNA JAKO PRZESTRZEŃ DEBATY NAD PROBLEMATYKA PŁCI W REGIONIE MENA
}

Słowa kluczowe: orientalizm, płeć, sztuka wizualna, Bliski Wschód, Afryka Północna

Walka z negatywną percepcją kobiecości jest jednym z zasadniczych tematów podejmowanych przez osoby zajmujące się problemem ujęcia, z jakim muszą się mierzyć kobiety w regionie Bliskiego Wschodu i Afryki Północnej (MENA)². Nie wynika to wyłącznie z kontestacji tradycji własnej kultury, ale także ze ścierania się „wyobrażeń" wytworzonych na przestrzeni czasu przez szeroko rozumianego odbiorcę zachodniego, który w wielu praktykach regionu upatrywał mechanizmów uwłaczających kobiecym prawom i swobodom.

Problematyka ciała zanurzona jest w głębszej naukowej refleksji o ludzkiej jednostce, stanowiąc medium manifestacji dylematów współczesności ${ }^{3}$. Ciało kobiece w obszarze Bliskiego Wschodu i Afryki Północnej jest przestrzenią nieustannej kontroli i oceny z perspektywy honoru, którego wedle lokalnych zasad kobieta jest głównym nośnikiem. Pojęcie to pozostaje głęboko utrwalone $\mathrm{w}$ regionie i rzutuje na dynamikę relacji społecznych. Idea honoru narodowego rozwijała się w świecie arabskim w odniesieniu do kolonialnych polityk realizowanych przez imperialne mocarstwa, szczególnie Wielką Brytanię i Francję. „W okresie rozwoju ruchów

${ }^{1}$ Dr; Uniwersytet Jagielloński; ORCID: 0000-0002-6245-8733; karolina.rak@uj.edu.pl.

${ }^{2}$ Akronim Middle East North Africa.

${ }^{3}$ N. Mrówczyńska-Rezmer, Przestrzenie ciała $w$ „kulturze płynnej nowoczesności”. Wyznaczanie granic ciała u źródeł nowoczesności, „humanistica 21” 2007, t. 1, s. 282. 
narodowowyzwoleńczych honor urósł do rangi wspólnej sprawy, a jego najbardziej namacalnym i widocznym przejawem było pojęcie honoru rodzinnego, opartego na kobiecej czystości”" ${ }^{\prime \prime}$.

Ze względu na swoją siłę witalną i wdzięk kobieta jest postrzegana jako zagrożenie, a jej ciało przedstawiane w kategorii haram - tego, co święte, ale również zakazane ${ }^{5}$. Kobiece ciało ujmowane jest niejako $z$ definicji jako erotyczne i kuszące. Ciało męskie postrzegane jest przez pryzmat odgrywanych ról, jako niosące ze sobą różnego typu odpowiedzialność, choćby ekonomiczną, jako żywiciela rodziny, albo polityczną, zarówno w przestrzeni decyzji, jak i kontestacjí.

Niniejszy tekst nie skupia się jednak na opisie lokalnej rzeczywistości, stanowiąc zaproszenie do podjęcia wraz z artyst(k)ami wizualnego ćwiczenia polegającego na de-orientalizacji symboliki ciała w sztuce. Obrazowanie ciała we współczesnej arabskiej sztuce stanowi odbicie wielowątkowych kontekstów politycznych, społecznych, lokalnych dyskursów religijnych. Przedstawianie ciała wpisane jest $w$ takie obszary jak władza, ponieważ ciało „zanurzone jest też bezpośrednio w sferze polityki, stosunki władzy wpływają na nie wprost"7.

Feministyczna narracja postkolonialna jest realizowana poprzez media wizualne, ukazując funkcjonowanie osób w ramach opresyjnego społeczeństwa przy jednoczesnym kwestionowaniu orientalistycznych klisz utrwalających obraz lokalnych społeczności kobiecych jako pasywnych i wpisując dynamikę ich egzystencji $w$ dychotomiczny mechanizm polaryzacji: zasłaniania-odsłaniania, obecności-nieobecności, widoczności-niewidoczności, przestrzeni publicznej-prywatnej.

${ }^{4} \mathrm{~K}$. Rak, Moje ciało to nie twój honor - problematyka kobiecego ciała w badaniach arabskiego ruchu emancypacyjnego na tle działań aktywistycznych w regionie MENA, [w:] Problemy społeczno-polityczne Bliskiego i Dalekiego Wschodu, red. A. Jelonek, M. Lipa, Kraków 2020, s. 75, zob. także B. Baron, Egypt as a Woman. Nationalists, Gender, and Politics, Berkeley 2005, s. 40.

${ }^{5}$ K. Rak, Moje ciało to nie twój honor..., op. cit., s. 73.

${ }^{6}$ K. van Nieuwkerk, Changing Images and Shifting Identities. Female Performers in Egypt, [w:] Images of Enchantment. Visual and Performing Arts of the Middle East, red. Sh. Zuhur, Cairo 1998, s. 28.

${ }^{7}$ N. Mrówczyńska-Rezmer, Przestrzenie..., op. cit., s. 283. 


\section{O RÓŻNYCH WYMIARACH „SPOGLĄDANIA”}

Baya Mahieddine (właśc. Fatima Haddad) to jedna z najbardziej znanych i cenionych artystek algierskich. Czerpała z własnych osobistych doświadczeń i wyobrażeń, w krótkim czasie stając się muzą takich postaci jak André Breton czy Pablo Picasso. Zainspirowany jej spontanicznością i naturalnym talentem Picasso zaprosił ją do współpracy w 1948 roku. Powszechnie uważa się, że jego seria Kobiety Algieru jest inspirowana twórczością Mahieddine. Podobnie jak Picasso, André Breton pozostawał pod silnym wrażeniem prac Algierki. Opisywał pojawiające się na jej obrazach odważne kolory i wyraziste kobiece postaci jako realizację surrealistycznej wizji sennej.

Sama Baya odmawiała określania siebie za pomocą terminologii z kanonu zachodniego, zdominowanego przez postawy orientalizujące i egzotyzujące osoby z przestrzeni Bliskiego Wschodu i Afryki Północnej, zwłaszcza kobiety ${ }^{8}$. Sana Makhoul w tekście poświęconym algierskiej artystce słusznie zwraca uwagę na problem definiowania i kategoryzowania dzieł sztuki pochodzących z kultur niezachodnich poprzez narzucenie im zachodnich definicji i terminologii ${ }^{9}$. Baya w wywiadach wielokrotnie mówiła o znaczeniu miejsca, z którego się wywodziła, wpływie tradycji i wspomnień na jej własną sztukę, podkreślając swoją algierskość jako element własnej artystycznej tożsamości.

Radykalny obraz kobiety znany jako Femme robe jaune cheveux bleus (Kobieta o niebieskich włosach i w żółtej sukience) ${ }^{10}$ Baya Mahieddine stworzyła w wieku 16 lat. Ten portret jest wspaniałą apoteozą kobiecej siły i witalności. Alexxa Gotthardt w analizie tego niezwykłego dzieła pisze o prawdziwej kobiecie, świadomej samej siebie, swojej mocy, seksualności ${ }^{11}$. Ta władcza bogini-królowa patrzy bezpośrednio na widza dużymi, przeszywającymi oczami. Algierska pisarka Assia Djebar w eseju poświęconym Bayi

${ }^{8}$ N. Boas, Baya. The Naked Eye, [w:] Baya. Woman of Algiers, red. N. Boas, New York, NY 2017, s. 9.

${ }^{9}$ S. Makhoul, Baya Mahieddine. An Arab Woman Artist, 23 IX 2007, http://djamelmoktefi.blogspot.com/2007/09/baya.html (dostęp 1 II 2021).

${ }^{10}$ Obraz udostępniony w katalogu https://greyartgallery.nyu.edu/wp-content/uploads/2017/12/Layout_Baya_20171206_lores.pdf (dostęp 1 II 2021).

${ }^{11}$ A. Gotthardt, The Algerian Teenager Who Painted a World of Liberated Women in 1940s Paris, 5 II 2018, https://www.artsy.net/article/artsy-editorial-algerian-teenagerpainted-liberated-women-1940s-paris (dostęp 1 II 2021). 


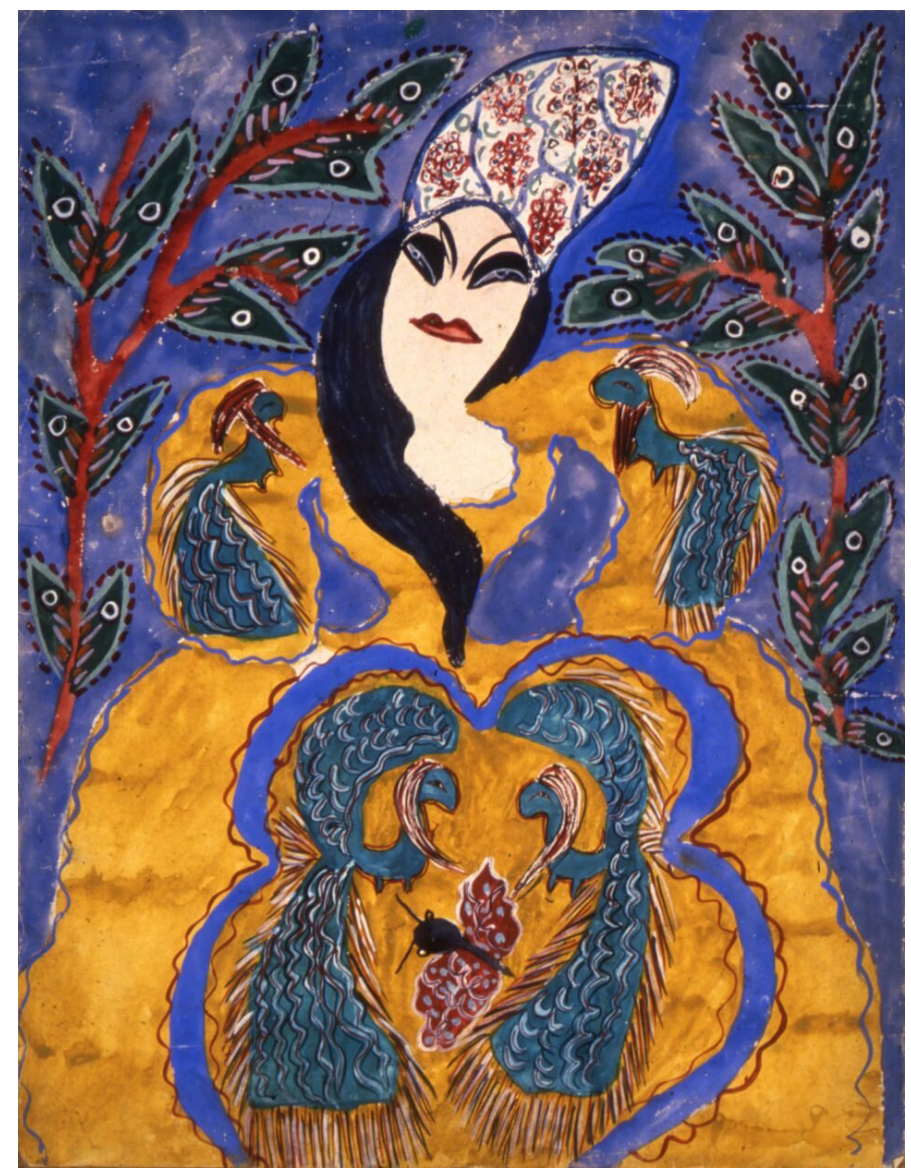

II. 1. Baya Mahieddine, Femme robe jaune cheveux bleus (Kobieta o niebieskich włosach i w żółtej sukience), 1947, gwasz, z kolekcji Adriena Maeght, zdjęcie Galerie Maeght

podkreśla, że kluczem do zrozumienia zamysłu artystki są właśnie te przykuwające wzrok oczy. To „wyzwolone oko”, jak opisała je Djebar, to swoista gra, którą z widzem podejmuje sama Baya - reprezentuje odwrócenie męskiego spojrzenia i jego odbioru kobiety ${ }^{12}$. Baya zdaje się rzucać tu wyzwanie orientalistycznym konwencjom, wedle których kobiety jawiły się jako

${ }^{12}$ A. Djebar, Baya, the Flower Gaze, [w:] Baya. Woman of Algiers, op. cit., s. 30. 
ponętne i pasywne figury. Djebar dostrzega tu silną krytykę zachodnich artystycznych konwencji i voyeurystycznych interpretacji, ale i kontestację rodzimej kultury, mocno ograniczającej swobodę i autonomię kobiecą.

Debata nad problematyką płci w kontekście świata arabskiego oraz szerzej pojętego regionu Bliskiego Wschodu i Afryki Północnej ukazuje, jak wyraźną pozostaje kwestia „wyobrażeń” będących częścią spuścizny europejskiej polityki kolonialnej.

W latach 70., w klasycznej już dla dziedziny badań nad regionem Bliskiego Wschodu i Afryki Północnej pracy Orientalizm, intelektualista palestyńskiego pochodzenia Edward W. Said opisał imperialną dynamikę opartą na Foucaultowskiej relacji wiedzy i władzy ${ }^{13}$. Intelektualni architekci europejskiej polityki dominacji przedstawiali Orient jako przestrzeń niezwykle sensualną, tajemniczą i magiczną, ale i podatną na władzę oraz obce wpływy. Zachód w tej opozycji prezentowany był jako silny, zmaskulinizowany, władczy.

Przestrzenią, w której wizualnie dostrzec da się owe napięcia pomiędzy lokalną społecznością a kolonizatorem, jest niewątpliwie Algieria. Marnia Lazreg w odniesieniu do tamtejszych doświadczeń pisze: „Historia polityczna miejscowych kobiet od XIX wieku to konfrontacje ideologiczne między mężczyznami, między teologami i politykami francuskimi a algierskimi, przywódcami rządu i opozycji. Te konfrontacje były wytworem złożonej interakcji czynników ekonomicznych, politycznych i kulturowych"14.

Podczas 132-letniej okupacji Algierii francuscy kolonialiści wykorzystywali ciała kobiet jako symboliczne pole walki. Formą przejawu władzy była polityka propagowania odsłaniania kobiecego ciała - jako sposobu zdominowania lokalnej rzeczywistości poprzez zaproponowanie nowego modelu społecznego. Ta kolonialna strategia rytualnego odsłonięcia była interpretowana jako forma uzyskania kontroli nad „nieznanym”, uznawanym za potencjalne zagrożenie. Kolonialna administracja używała takich mechanizmów, by ukazać dotychczasowe struktury społeczne jako wsteczne i nienowoczesne ${ }^{15}$.

${ }^{13}$ Said odwoływał się w swoich pracach także do idei Antonia Gramsciego, nie poprzestając wyłącznie na ukazaniu relacji siły kolonizatora i skolonizowanego, ale podkreślaniu dyskursu postkolonialnego.

${ }^{14}$ M. Lazreg, Gender and Politics in Algeria. Unraveling the Religious Paradigm, „Signs" 1990, t. 15, nr 4, s. 756.

${ }^{15}$ M. Yeğenoğlou, Colonial Fantasies. Towards a Feminist Reading of Orientalism, Cambridge 1998. 


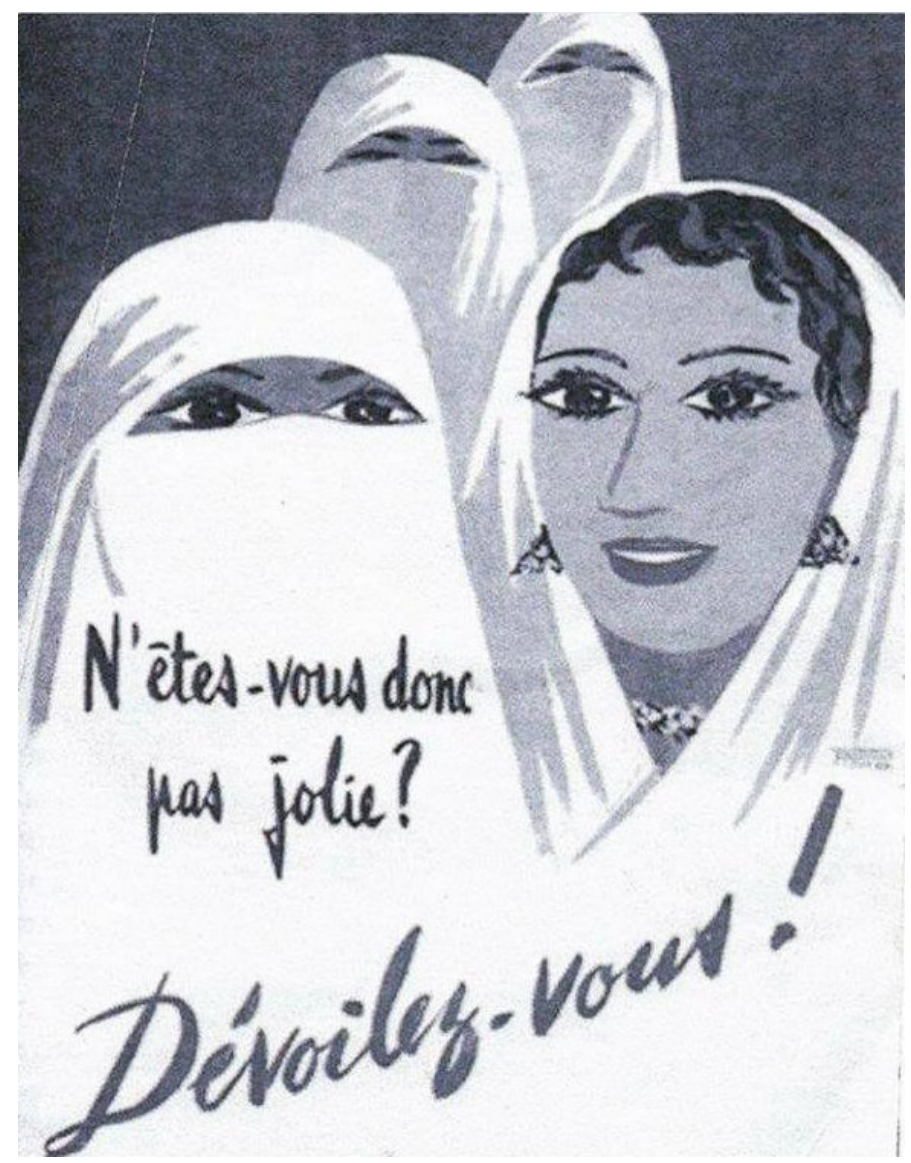

II. 2. Plakat propagandowy N'êt tes-vous donc pas jolie? Dévoilez-vous! (Czyż nie jesteście piękne? Odsłońcie się!), około 1950-1960

Jednym z udokumentowanych wizualnych przykładów tej polityki jest plakat przedstawiający kobiety okryte tradycyjnym haikiem ${ }^{16}$. Plakat ma propagandowy wymiar - zadawać ma pozornie niewinne pytanie: „Czyż nie jesteś piękna? Odsłoń się" - jednak głębszy kontekst takiego działania sprowadzał się wedle Frantza Fanona do próby dywersji lokalnej tradycji,

${ }^{16}$ Haik - tradycyjna odzież wierzchnia drapowana na głowie i ciele kobiety. 


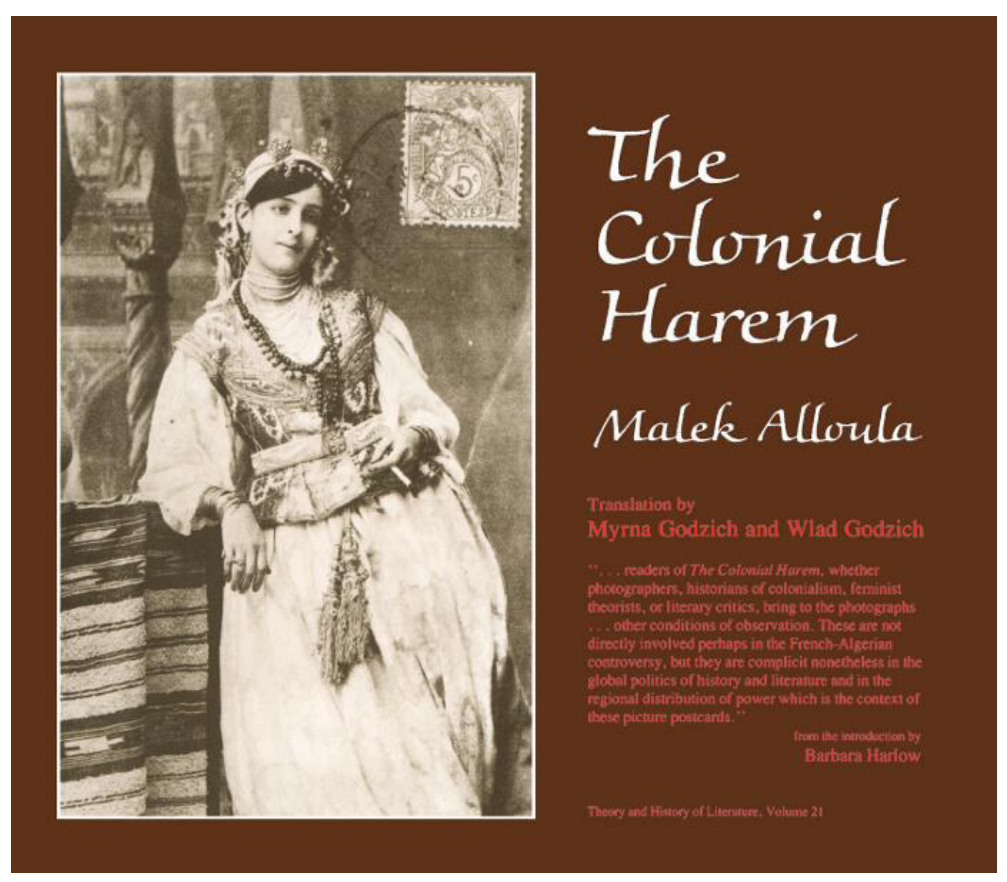

II. 3. Okładka The Colonial Harem, Malek Alloula

przedstawienia jej w negatywnym świetle, w konsekwencji kontroli nad społeczeństwem prowadzącej do rugowania kultury algierskiej ${ }^{17}$.

Nie mniej interesującym materiałem są szeroko opisywane pocztówki produkowane w okresie kolonialnym, których analiza dostarczyła badaczom bogatego materiału na temat tworzenia „wyobrażeń” i zniekształcania rzeczywistości. Jedną z najbardziej skrupulatnych prac opisujących to zjawisko pozostaje książka algierskiego poety, pisarza i krytyka literackiego Maleka Allouli.

W The Colonial Harem (Kolonialny harem) Alloula analizuje pocztówki przedstawiające "egzotyczne” zdjęcia algierskich kobiet, które w latach 1900-1930 produkowali francuscy przedsiębiorcy. Według niej pocztówki wizualnie przedstawiają relacje władzy między skolonizowanymi a kolonizatorami. Książka zawiera bogaty komentarz do zdjęć wykonanych w trakcie trwania francuskiego reżimu kolonialnego, zwłaszcza tych

${ }^{17}$ F. Fanon, Algeria Unveiled, [w:] Decolonization. Perspectives from Now and Then, red. P. Duara, London 2003, s. 42-55. 


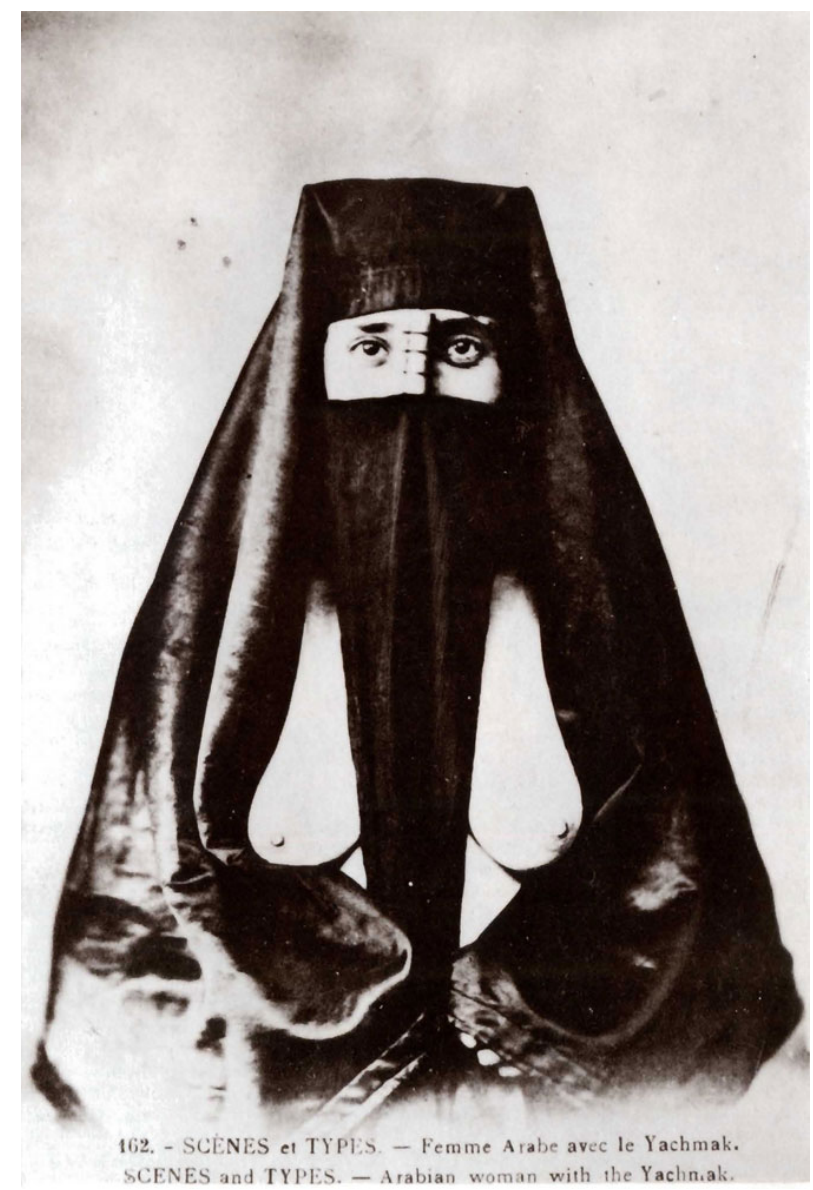

II. 4. Pocztówka: kobieta w yashmaku, źródło zdjęcia: https://veil.unc.edu/arts/visual-arts/ orientalist-photography/colonial-harem/

przedstawiających erotyzowane sceny z udziałem algierskich kobiet. Według Allouli była to projekcja kolonialnej rzeczywistości, która nigdy nie istniała.

Przykładem alteracji rzeczywistości jest surrealistyczna pocztówka przedstawiająca algierską kobietę w zasłonie typu yashmak ${ }^{18}$, przeznaczo-

18 Zasłona pochodząca z terenów Turcji. Zdjęcie ze strony https://veil.unc.edu/arts/ visual-arts/orientalist-photography/colonial-harem/ (dostęp 1 II 2021). 


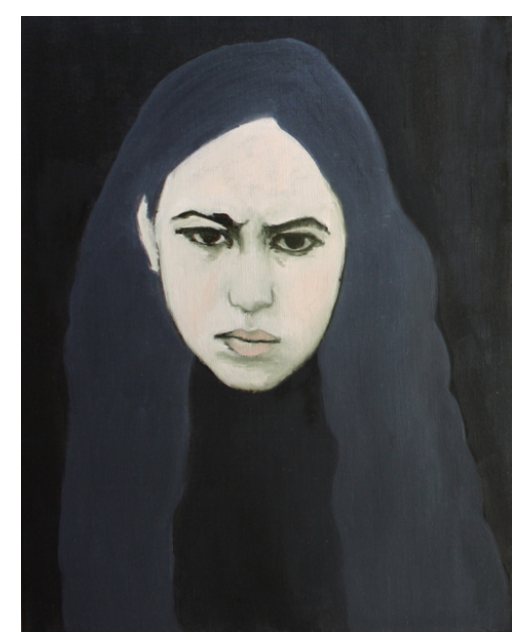

II. 5. Dalila Dalléas Bouzar, Princesse (Księżniczka), 2015-2016, obraz, olej na płótnie, źródło zdjęcia: http://www.daliladalleas.com/neu/index.php?/ ongoing/princesse/

nej do owinięcia górnej i dolnej części twarzy tak, by odsłonięte pozostały tylko oczy. Jednak zasłona w przypadku tego zdjęcia jest niewłaściwie wystylizowana: policzki kobiety i większość jej nosa są widoczne, podczas gdy czarny materiał wpada między jej odsłonięte piersi. To erotyczne zdjęcie nie ma na celu pokazania kobiety $w$ tradycyjnym otoczeniu, jest raczej narzędziem służącym przyciągnięciu uwagi obserwatora. Osoba na fotografii staje się uprzedmiotowiona i tylko jej oczy przyciągają spojrzenie widza z powrotem w stronę jej twarzy.

W przestrzeni algierskiej, ze względu na wielopoziomową sieć doświadczeń, nie brak współczesnych prac będących próbą kontestowania sposobu przedstawiania lokalnej rzeczywistości, zwłaszcza w kontekście rozliczeń okresu dominacji francuskiej. Algierska artystka Dalila Dalléas Bouzar w serii Princesse bierze na kanwę historię słynnych fotografii wykonanych przez Marca Garangera na zlecenie francuskiej administracji ${ }^{19}$. To historia o portretach wbrew woli. O naruszeniu autonomii. Ale to też historia o spojrzeniach, które wedle wspomnień samego fotografa były „jak pociski”.

${ }^{19}$ D. Dalléas Bouzar, Princesse, http://www.daliladalleas.com/neu/index.php?/ongoing/princesse/ (dostęp 1 II 2021). 
Garanger na zlecenie francuskiego dowództwa w ciągu dziesięciu dni wykonał około dwóch tysięcy portretów, które miały służyć jako środek identyfikacji. Seria kobiecych portretów pozbawionych zasłon, z widocznymi ochronnymi tatuażami, cechuje się sztywnością ich pozy i niesłychaną intensywnością spojrzeń, w których widoczne są rozmaite negatywne uczucia, od niechęci do złości. Dodatkowym elementem wyostrzającym odbiór fotografii jest surowe białe tło ściany, na której zostaty one wykonane ${ }^{20}$.

Karina Eilaraas przywołuje konotacje z omawianymi przez Alloulę pocztówkami, które zdają się co najmniej wtargnięciem w przestrzeń prywatną, intymność ${ }^{21}$. W swoich portretach, wykonanych jakby na przekór na ciemnym tle, Dalléas Bouzar wspaniale oddaje te detale, które czynią osoby na fotografiach rozpoznawalnymi.

Polityka sprzężona była w projekcie kolonialnym z nauką oraz sztuką. Dzieła tamtego okresu ugruntowały szereg klisz, przez których pryzmat obserwowano przestrzeń Bliskiego Wschodu i Afryki Północnej. Trzy z tych klisz stanowią przyczynek dla dalszych rozważań. Jest to postać tancerki, odaliski oraz przestrzeń hammamu, czyli łaźni, które stają się punktem odniesienia dla lokalnych artystów i artystek oraz ich prób dekonstrukcji orientalistycznych wizji, pokazujących swoim odbiorcom nowe formy interpretacji.

Projekt wizualny Dansons algierskiej artystki Zoulikhi Bouabdellah to forma kontestacji dynamiki relacji Francji z Maghrebem. Artystka przedstawia w ironizującej (dla niektórych odbiorców może w lekko skandalizującej) formie zarówno perspektywę historyczną doświadczenia kolonialnego, jak i postkolonialną rzeczywistość, nadal przesiąkniętą postawami orientalizującymi.

Łącząc symbole o charakterze narodowym - w postaci trójkolorowej chusty jako elementu stroju oraz Marsylianki jako podkładu muzycznego z motywem tancerki brzucha, kojarzonym z kulturą arabską, Bouabdellah kwestionuje postrzeganie tożsamości francuskiej i północnoafrykańskiej jako wzajemnie się wykluczających. Gra skojarzeń podjęta przez artystkę

${ }^{20}$ C. Naggar, Women Unveiled. Marc Garanger's Contested Portraits of 1960s Algeria, „Time” 23 IV 2013, https://time.com/69351/women-unveiled-marc-garangerscontested-portraits-of-1960s-algeria/ (dostęp 1 II 2021).

${ }^{21} \mathrm{~J}$. Howell, Decoding Marc Garanger's Photographic Message in La Guerre d'Algérie vue par un appelé du contingent, „Dalhousie French Studies” 2010, t. 92, s. 85. 


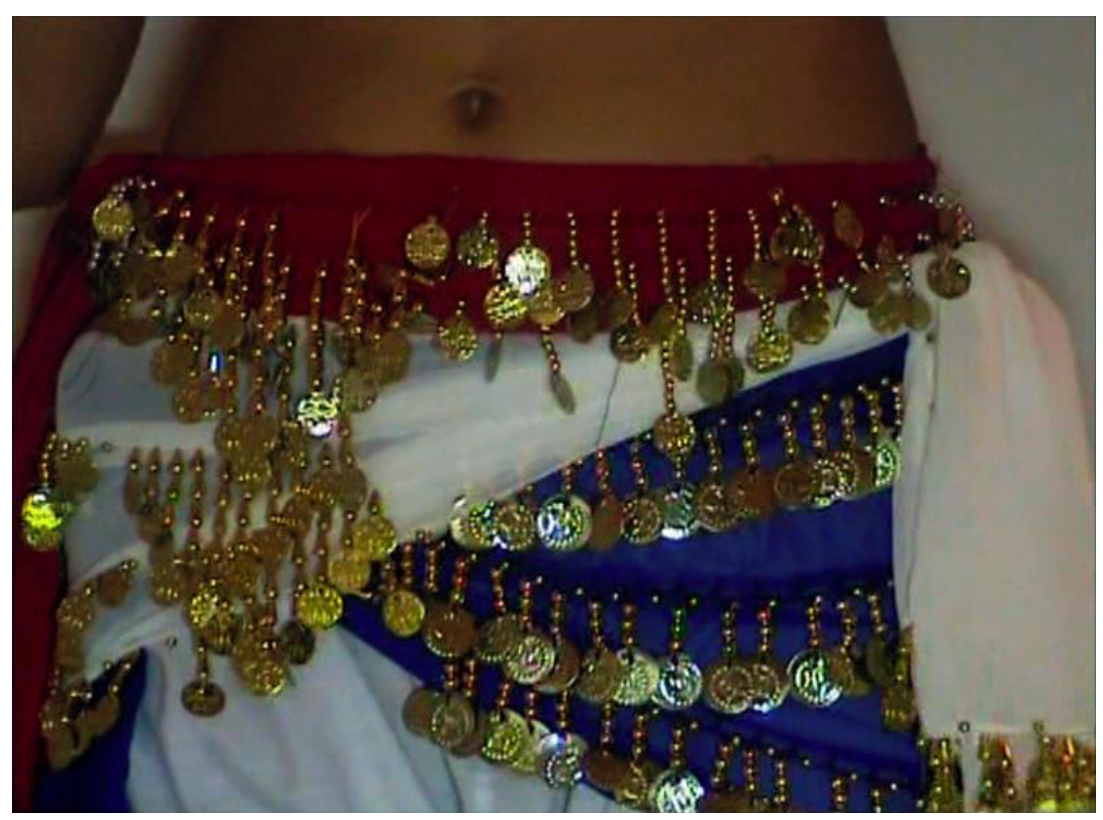

II. 6. Zoulikha Bouabdellah, Dansons (Zatańczmy), 2003, wideo z podkładem dźwiękowym, 5 min, źródło zdjęcia: https://www. centrepompidou.fr/fr/ressources/oeuvre/cBLdeg

z widzem opiera się na wykorzystaniu dosłownie paru opozycji - elementów "francuskich" i „arabskich", celowo budzących skojarzenia z kulturami kolonizatorów oraz skolonizowanych: publiczny "męski” świat polityki i historii uwidoczniony w barwach i melodii hymnu oraz prywatny "kobiecy", tak chętnie ukazywany w malarstwie orientalistycznym pod postacią zmysłowej tancerki brzucha22.

La Grande Odalisque, neoklasyczny obraz autorstwa francuskiego malarza Jeana-Auguste'a-Dominique'a Ingres'a (1780-1867), znajdujący się w kolekcji Luwru, to prawdopodobnie jedno z najbardziej rozpoznawalnych dzieł orientalistycznych, ale także inspiracja dla arabskich artystów i artystek, podejmujących swoistą grę skojarzeń i skrupulatnie punktujących wszelkie wypaczenia, które w tego typu dziełach zostały zawarte.

22 S. Shilton, Belly Dancing to the Marseillaise. Zoulikha Bouabdellah's Dansons, „Contemporary French and Francophone Studies" 2008, t. 12, nr 4, s. 439. 


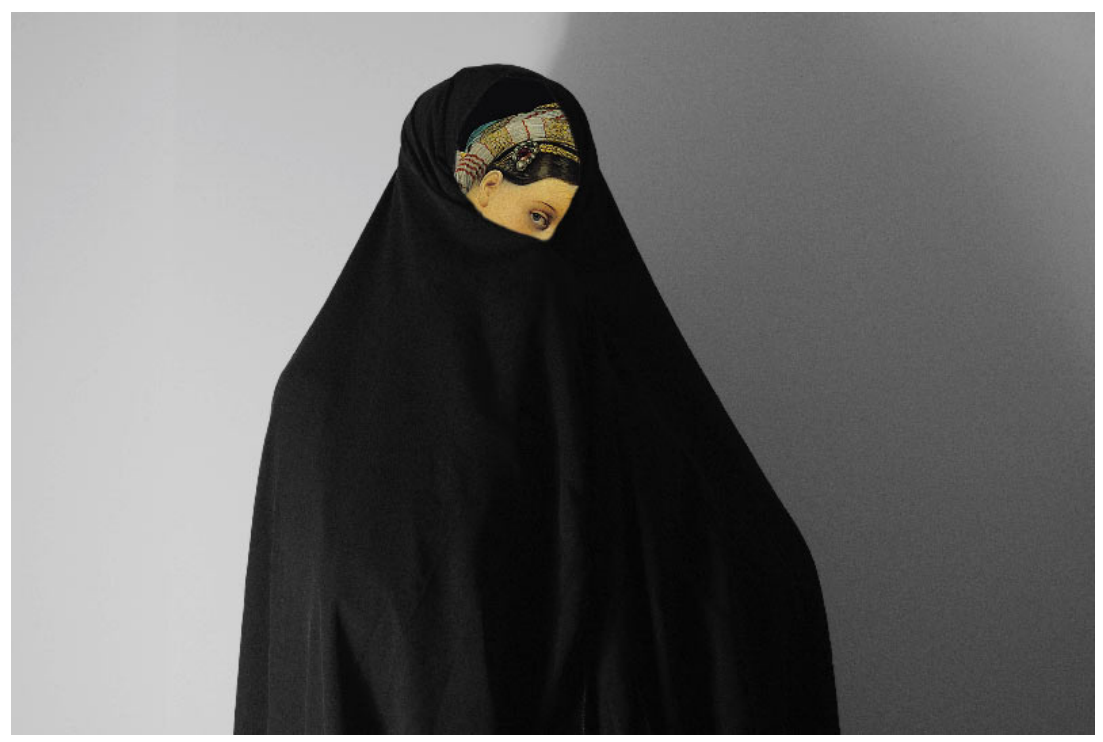

II. 7. Musa Al-Shadeedi (Irak), His Look (Jego spojrzenie), 2016, druk na papierze, źródło zdjęcia: http://artkuwait.org/2016/04/ dubai-abolish-article-153-exhibition-at-jamm-art-gallery.html

Iracki artysta Musa Al-Shadeedi skupił się na pewnym istotnym detalu, demonstrując symboliczne zniekształcenie. Postać kobieca została przez Ingres'a uchwycona z rzucającą się w oczy dysproporcją - dwoma lub trzema kręgami lędźwiowymi za dużo. Ostatnie badania wykazały, że jej wydłużony kręgosłup był celowym zniekształceniem, sposobem zwrócenia uwagi na uwodzicielską postawę jej ciała, mającą sprawiać przyjemność sułtanowi $^{23}$. Odbiorcę uderza wyraz jej twarzy, smutny i obojętny.

Al-Shadeedi używa obrazu jako punktu odniesienia. Wedle artysty współcześni mężczyźni nadal postrzegają kobiety jako ciała, które można wykorzystać dla własnej przyjemności, i jako własność prywatną ${ }^{24}$. Na jego fotografii kobieta jest uprzedmiotowiona. Słychać tu echo analizy Johna

23 J.-I. Maigne, G. Chatellier, H. Norloff, Extra vertebrae in Ingres' La Grande Odalisque, „Journal of Royal Society of Medicine” 2004, t. 97, nr 7, s. 342-344.

${ }^{24} \mathrm{~J}$. Kalsi, Artists Stand Up for Women's Rights, „Gulf News” 27 IV 2016, https://gulfnews.com/entertainment/arts-culture/artists-stand-up-for-womens-rights-1.1812896 (dostęp 1 II 2021). 
Bergera, który w Ways of Seeing, przyglądając się aktom, podkreśla, że kobiety są przedstawiane zupełnie inaczej niż mężczyźni - nie dlatego, że kobiecość różni się od męskości, ale dlatego, że zawsze zakłada się, iż idealnym widzem jest mężczyzna, a wizerunek kobiety ma na celu dostarczać mu przyjemności ${ }^{25}$.

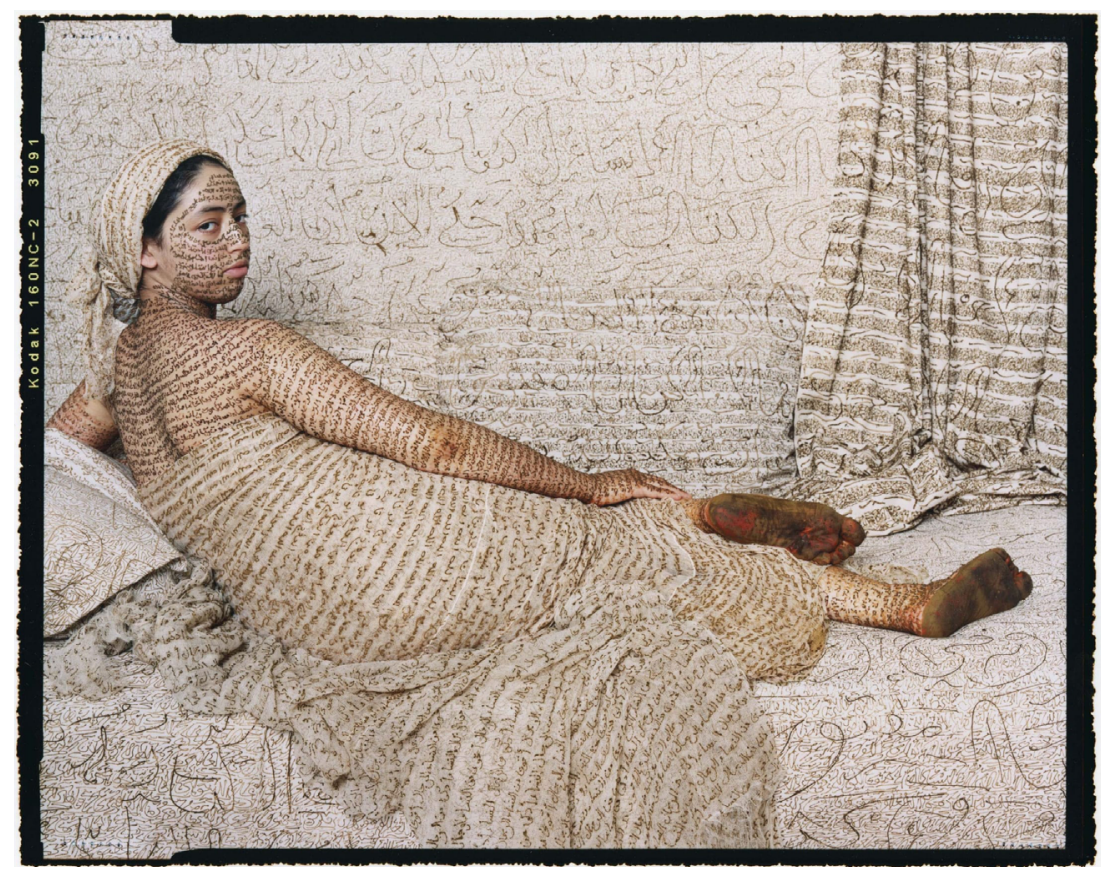

II. 8. Lalla Essaydi (Maroko), Les Femmes du Maroc. La Grande Odalisque (Kobiety Maroka. Wielka Odaliska), 2008, druk chromogeniczny, źródło zdjęcia: https://www.clevelandart.org/ art/2012.13

Marokańska artystka i fotografka Lalla Essaydi w cyklu Les Femmes du Maroc. La Grande Odalisque także bawi się grą skojarzeń z dziełem Ingre$\mathrm{s}^{\prime} \mathrm{a}^{26}$. Kobieta na portrecie zwraca twarz $\mathrm{w}$ stronę obiektywu, jej ciało jest

${ }^{25}$ J. Berger, Ways of Seeing, London 1972, s. 64.

${ }^{26}$ L. Essaydi, Les Femmes du Maroc. La Grande Odalisque, https://www.clevelandart.org/art/2012.13 (dostęp 1 II 2021). 
pokryte arabskim tekstem, zapisanym henną - Essaydi odnosi się do tradycji związanej ze specjalnymi uroczystymi wydarzeniami, takimi jak dojrzewanie, małżeństwo i narodziny pierwszego dziecka, kiedy ozdabia się stopy i dłonie podczas uroczystości kobiecych. Ciało kobiety przysłonięte jest tkaniną, spogląda ona krytycznie, z wyrzutem. Zdaje sobie sprawę z tego, że jest obserwowana, nadaremno szukać w jej spojrzeniu orientalistycznej chęci urzeczenia Widza.

Wizualna seria ujęć autorstwa jemeńsko-amerykańskiej artystki Yumny Al-Arashi to prawdziwa uczta estetyczna ${ }^{27}$. Przestrzenią projektu jest kobieca łaźnia, miejsce pielęgnacji, wypoczynku. Al-Arashi w subtelny sposób uchwyca prawdziwie siostrzany moment bezpiecznej i pięknej intymności, w której kobiety mogą poczuć się swobodnie, odetchnąć od codziennych obowiązków, ale i przytłaczających je oczekiwań. Jednak z perspektywy obserwatora Al-Arashi robi tu rzecz niezwykłą. Przede wszystkim odzyskuje przestrzeń. Hammam to jedna z ulubionych orientalistycznych klisz,

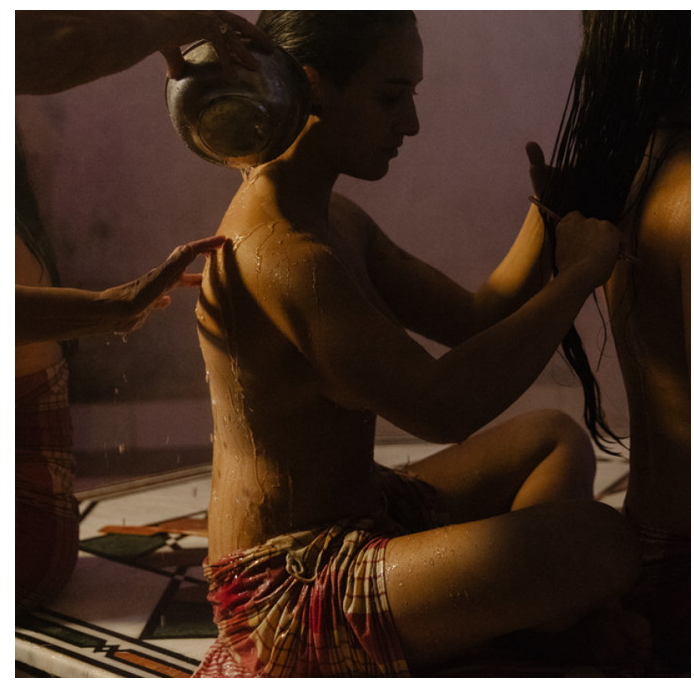

II. 9. Yumna Al-Arashi (Jemen, USA), ujęcie z projektu Shedding Skin (Zrzucajq̨c skórę), źródło projektu: https://vimeo.com/228396380

${ }^{27}$ Y. Al-Arashi, Shedding Skin, https://vimeo.com/228396380 (dostęp 1 II 2021). 
w których Obserwator dokonywał aktu agresji. Miał obserwować przestrzeń, która wedle tradycji i zwyczaju powinna być dla niego niedostępna. Tu Al-Arashi pozwala Obserwatorowi wejrzeć w intymność hammamu wraz $z$ nią. $W$ tym portrecie, skonstruowanym $z$ delikatnych miodowo-złotych barw, artystka powoli usuwa kolejno warstwy uprzedzeń ugruntowanych wobec kobiet zarówno w lokalnych społeczeństwach, jak i w zewnętrznym odbiorze, choćby poprzez medialne obrazy.

Kobiety w hammamie skupione są na sobie samych, na własnych rytuałach. Obserwator, którego wprowadza Al-Arashi, nie wzbudza żadnego zainteresowania. Artystka nie pozostawia Widza z samym obrazem, ale także z interesującą narracją. Opowiada Widzowi, kim ona jest, odnosi się do stereotypów. W tym swoistym akcie dywersji postać znana Obserwatorowi $z$ orientalistycznych ujęć nabiera feministycznej mocy, ukazując uniwersalność kobiecości samej w sobie, niedefiniowanej poprzez doświadczenia bycia „matką", „siostrą" czy „żoną". Zachwycające fotografie stanowią apoteozę kobiecej seksualności, siły i piękna, będąc w kontrze do powszechnego odbioru kobiecego ciała jako mającego dostarczać zmysłowej przyjemności Obserwatorowi albo społecznego dyscyplinowania.

\section{PODSUMOWANIE}

Przez lata kobieca cielesność w badaniach nad ruchami emancypacyjnymi w regionie Bliskiego Wschodu i Afryki Północnej „ukazywana była jako symbol lokalnej demarkacji uległości o charakterze kulturowym, jako nośnik wartości moralnych, jak i politycznych, utrwalając $w$ ten sposób dominujący dyskurs zmaskulinizowanej przestrzeni publicznej"28. W latach po Arabskiej Wiośnie 2010/2011 wyraźnie dostrzec można zmiany narracji, także akademickiej, skupiające się na ukazywaniu podmiotowości kobiet oraz ich rosnącego zaangażowania społeczno-politycznego.

Praktyki artystyczne regionu Bliskiego Wschodu i Afryki Północnej, zawierające mocny feministyczny przekaz równościowy, stały się przestrzenią badań otwierających nas na pytanie o to, jak rozwija się narracja wokół kobiecego ciała. Niezwykle prężnie rozwijająca się scena artystyczna świata arabskiego pozwala na ukazanie dynamiki ścierania się wzorców

${ }^{28}$ K. Rak, Moje ciało to nie twój honor..., op. cit., s. 69. 
i oczekiwań, zarówno w kontekście lokalnych tradycji i uwarunkowań społeczeństw opartych na systemie patriarchalnym, jak i zachodnich wyobrażeń, wyrosłych z tradycji orientalizmu, co stanowi o niezwykle bogatej mozaice doświadczeń.

Sztuka wizualna regionu Bliskiego Wschodu i Afryki Północnej stała się ważnym medium debaty nad kwestiami płci, rolami społecznymi i autonomią jednostki, nie tylko w kontekście lokalnej przestrzeni, ale i w odniesieniu do przekazu, który odbierany jest poza jej granicami.

Maya Mikdashi w tekście How Not to Study Gender in the Middle East podkreśla, że to, co nazywamy „kanonem feministycznym”, może zawierać w sobie także przykłady wykluczenia i imperialnych historii. Stąd kluczowa wydaje się krytyczna u swej podstawy świadomość istnienia mechanizmów postrzegania świata z perspektywy opozycji ,ja” i „inny" oraz gotowość ich przezwyciężania ${ }^{29}$.

\section{BIBLIOGRAFIA}

Alloula M., The Colonial Harem, Minneapolis, MN 1986, https://doi.org/10.5749/j.cttth83.

Berger J., Ways of Seeing, London 1972.

Baron B., Egypt as a Woman. Nationalists, Gender, and Politics, Berkeley 2005.

Boas N., Baya. The Naked Eye, [w:] Baya. Woman of Algiers, ed. N. Boas, New York, NY 2017.

Djebar A., Baya, the Flower Gaze, [w:] Baya. Woman of Algiers, red. N. Boas, New York, NY 2017.

Fanon F., Algeria Unveiled, [w:] Decolonization. Perspectives from Now and Then, red. P. Duara, London 2003, s. 42-55.

Howell J., Decoding Marc Garanger's Photographic Message in La Guerre d'Algérie vue par un appelé du contingent, „Dalhousie French Studies” 2010, t. 92, s. 85-95.

Lazreg M., Gender and Politics in Algeria. Unraveling the Religious Paradigm, "Signs" 1990, t. 15, nr 4, https://doi.org/10.1086/494627.

Maigne J.-I., Chatellier G., Norloff H., Extra vertebrae in Ingres' La Grande Odalisque, „Journal of Royal Society of Medicine" 2004, t. 97, nr 7, s. 342-344, https://www.ncbi.nlm.nih.gov/ pmc/articles/PMC1079534/ (dostęp 1 II 2021).

Mikdashi M., How Not to Study Gender in the Middle East, „Jadaliyya” 21 III 2012, https:// www.jadaliyya.com/Details/25434 (dostęp 1 II 2021).

Mrówczyńska-Rezmer N., Przestrzenie ciała $w$ „kulturze płynnej nowoczesności”. Wyznaczanie granic ciała u źródet nowoczesności, „humanistica 21” 2007, t. 1, s. 281-298.

${ }^{29}$ M. Mikdashi, How Not to Study Gender in the Middle East, „Jadaliyya” 21 III 2012, https://www.jadaliyya.com/Details/25434 (dostęp 1 II 2021). 
Nieuwkerk K. van, Changing Images and Shifting Identities. Female Performers in Egypt, [w:] Images of Enchantment. Visual and Performing Arts of the Middle East, red. Sh. Zuhur, Cairo 1998, s. 21-36.

Rak K., Moje ciało to nie twój honor - problematyka kobiecego ciała $w$ badaniach arabskiego ruchu emancypacyjnego na tle działań aktywistycznych w regionie MENA, [w:] Problemy społeczno-polityczne Bliskiego i Dalekiego Wschodu, red. A. Jelonek, M. Lipa, Kraków 2020, s. 67-84.

Said E.W., Orientalizm, tłum. M. Wyrwas-Wiśniewska, Poznań 2018.

Sellers-Young B., Edward Said and Tahia Carioca. Performing From a Place of Exile Or a Place of Home, "The International Journal of Arts Theory and History" 2015, t. 9, nr 2, https:// doi.org/10.18848/2326-9952/CGP/v09i02/36265.

Shilton S., Belly Dancing to the Marseillaise. Zoulikha Bouabdellah's Dansons, "Contemporary French and Francophone Studies" 2008, t. 12, nr 4, s. 437-444, https://doi. org/10.1080/17409290802447464.

Yeğenoğlou M., Colonial Fantasies. Towards a Feminist Reading of Orientalism, Cambridge 1998, https://doi.org/10.1017/CBO9780511583445.

\section{Netografia}

Al-Arashi Y., Shedding Skin, https://vimeo.com/228396380 (dostęp 1 II 2021).

Al-Tahawy M., Writing the Body and the Rhetoric of Protest in Arab Women's Literature, przeł. Shoshana London Sappir, 2017, https://levantine-journal.org/writing-body-rhetoricprotest-arab-womens-literature/ (dostęp 1 II 2021).

Dalléas Bouzar D., Princesse, http://www.daliladalleas.com/neu/index.php?/ongoing/princesse/ (dostęp 1 II 2021).

Essaydi L., Les Femmes du Maroc. La Grande Odalisque, https://www.clevelandart.org/ art/2012.13 (dostęp 1 II 2021).

Gotthardt A., The Algerian Teenager Who Painted a World of Liberated Women in 1940s Paris, 5 II 2018, https://www.artsy.net/article/artsy-editorial-algerian-teenager-paintedliberated-women-1940s-paris (dostęp 1 II 2021).

Honig A., Pins and Needles, 2010, https://hayvkahraman.com/2017/01/22/pins-and-needles-ana-finel-honig-2010/ (dostęp 1 II 2021).

Kalsi J., Artists Stand Up for Women's Rights, „Gulf News” 27 IV 2016, https://gulfnews.com/entertainment/arts-culture/artists-stand-up-for-womens-rights-1.1812896 (dostęp 1 II 2021).

Makhoul S., Baya Mahieddine. An Arab Woman Artist, 23 IX 2007, http://djamelmoktefi.blogspot.com/2007/09/baya.html (dostęp 1 II 2021).

Naggar C., Women Unveiled. Marc Garanger's Contested Portraits of 1960s Algeria, „Time” 23 IV 2013, https://time.com/69351/women-unveiled-marc-garangers-contested-portraits-of1960s-algeria/ (dostęp 1 II 2021).

Said E., Homage to a Belly Dancer, ,London Review of Books" 1990, t. 12, nr 17, https://www. Irb.co.uk/the-paper/v12/n17/edward-said/homage-to-a-belly-dancer?referrer=https\%3A\%2F\%2Fwww.google.com\%2F (dostęp 1 II 2021).

Sentilles S., Postcolonial Postcards and Women as Props for War-making, ",The New Yorker" $5 \mathrm{X}$ 2017, https://www.newyorker.com/books/second-read/colonial-postcards-and-womenas-props-for-war-making (dostęp 1 II 2021). 


\title{
ON THE DE-ORIENTATION OF THE „GAZE” VISUAL ART AS A SPACE FOR GENDER DEBATE IN THE MENA REGION
}

\begin{abstract}
Contesting the problematic perception of femininity within the Middle East and North Africa through the medium of art is not only a result of questioning the traditions of one's own culture, but is strongly connected to the issue of the "imagery of the Orient" and the Western gaze, especially visible throughout the colonial era in the region. This text is an invitation to undertake a visual exercise with the artists, leading to a process of de-orientalising the symbolism of the body in art practices.
\end{abstract}

Keywords: Orientalism, gender, visual arts, Middle East, North Africa 